\title{
EDitoriol EDitoriol
}

\section{A CONSTRUÇÃO DE UM PROJETO CLASSISTA DE EDUCAÇÃO E OS DESAFIOS PARA O SERVIÇO SOCIAL}

\author{
Ana Paula Ornellas Mauriel* \\ Adrianyce Angélica Silva de Sousa** \\ Maria Liduína de Oliveira e Silva*** \\ Renato dos Santos Veloso****
}

É com grande satisfação que apresentamos o $35^{\circ}$ volume da Revista Temporalis, cujo tema se dedica a discutir a construção de um projeto classista de educação e os desafios para o Serviço Social. A escolha pelo mesmo tema da Oficina Nacional realizada entre 7 e 9 de novembro de 2017, na Universidade Federal Fluminense teve a pretensão de avançar nos debates sobre as implicações da conjuntura à realidade das Instituições de Ensino Superior no que se refere ao financiamento e gestão, condições de trabalho, qualidade na formação e produção de conhecimento nos níveis da graduação e da pós-graduação e no que tange às especificidades da formação profissional em Serviço Social.

A Oficina Nacional da Associação Brasileira de Ensino e Pesquisa em Serviço Social (ABEPSS) que completou, em 2017, sua $16^{\mathrm{a}}$ edição, ocorre sempre no primeiro ano de cada gestão, configurando momento e espaço fundamentais para a articulação e reflexão política e acadêmica entre as diversas unidades de formação. Tais eventos envolvem temas necessários ao aprimoramento do projeto de formação profissional como também ao enfrentamento dos desafios colocados pela contrarreforma da educação superior e as transformações nas políticas socia is, em suas particularidades na graduação e na pós-graduação, proporcionando também o estímulo de várias frentes, como a abertura de novas parcerias institucionais, o intercâmbio de pesquisas e pesquisadores, o diálogo com as representações de Área na Coordenação de Aperfeiçoamento de Pessoal de Nível Superior (CAPES) e Conselho Nacional de Desenvolvimento Científico e Tecnológico (CNPq), fortalecendo a

\footnotetext{
* Assistente Social. Mestre em Serviço Social (UFRJ). Doutora em Ciências Sociais (UNICAMP). Professora da Escola de Serviço Social da Universidade Federal Fluminense (UFF).

** Assistente Social. Mestre em Serviço Social (UFPE). Doutora em Serviço Social (UFRJ). Profe ssora da Escola de Serviço Social da Universidade Federal Fluminense (UFF).

*** Assistente Social. Mestre e Doutora em Serviço Social (PUCSP). Professora no curso de Serviço Social da Universidade Federal de São Paulo (Unifesp).

**** Assistente Social. Mestre e Doutor em Serviço Social (UFRJ). Profe ssor da Faculdade de Serviço Social da Universidade do Estado do Rio de Janeiro (UERJ).
} 
articulação com outras entidades representativas da categoria e com movimentos sociais, dentre outras. As Oficinas Nacionais são precedidas por seis Oficinas regionais realizadas nas regiões estabelecidas institucionalmente segundo Estatuto da ABEPSS, as quais, por possuir mais capilaridade com as unidades de formação acadêmica, estimulam a reflexão e aprofundamento das temáticas centrais presentes na conjuntura brasileira que atingem a formação graduada e pósgraduada em Serviço Social.

A atual gestão da ABEPSS - "QUEM É DE LUTA, RESISTE” - herdeira de uma trajetória de conquistas constituídas pela ABEPSS ao longo de mais de 70 anos, tem como intuito, por meio de suas ações, lutar contra a precarização e aligeiramento da formação profissional, defender o trabalho docente com qualidade e contra o produtivismo e competitividade nas Unidades de Formação Acadêmica (UFAs), por meio de estratégias de articulação entre graduação e pós-graduação, no sentido da defesa do projeto ético-político profissional, compreendendo como essencial a unidade entre formação e exercício profissional.

Um desafio permanente da ABEPSS é acompanhar a implantação das Diretrizes Curriculares. Isso envolve pensar um processo de formação continuada, que venha a atingir os docentes e discentes de todas as universidades e/ou faculdades que tenha em seu quadro o curso de graduação em Serviço Social e/ou pós-graduação na área, integrando produção de conhecimento, formação e exercício profissional como meio necessário e urgente para que a implementação das Diretrizes não seja fraturada em seus elementos mais relevantes, e para que seus fundamentos não sejam diluídos em seus aspectos mais importantes.

Acreditando que o avanço das lutas contra a precarização e aligeiramento não pode findar com o espaço do evento, essa edição vem a público com o intuito de fortalecer o diálogo com a comunidade acadêmica e pesquisadores da área do Serviço Social para aprofundar reflexão coletiva com a publicação de temas candentes para a profissão, particularmente focando na educação superior brasileira e no Serviço Social na conjuntura atual, considerando as particularidades do capitalismo dependente, associadas ao aprofundamento das medidas neoliberais, que ampliam os desafios às concepções de educação superior e de universidade pautadas em princípios como autonomia didático-pedagógica, unidade entre ensino, pesquisa e extensão, gratuidade, igualdade de acesso e condições de permanência. Dialeticamente, este contexto requer reflexões que atentem para a educação superior como parte de um projeto societário classista daqueles/as que vivem do trabalho, enquanto totalidade, e como, no âmbito do Serviço Social brasileiro, aumentam os desafios ao projeto de formação profissional.

Considerando tais questões, a revista 35 está organizada em duas seções. A primeira delas formada por Artigos Temáticos engloba debates diretamente vinculados à chamada temática desta edição e a segunda organizada por uma seção de Temas Livres. 
Nessa dinâmica, a educação superior enquanto um projeto classista de financeiriza ção e mundialização do capital se configura como uma chave analítica de explicação do conjunto dos artigos temáticos elencados nesta edição. No primeiro deles, intitulados A contrarreforma do ensino superior brasileiro: determinantes históricos, as autoras Andressa Elisa Martos Antunes e Esther Luíza de Souza Lemos retomam a leitura dos clássicos do pensamento social no campo da tradição marxista para apreender a historicidade do sentido da educação e do acesso ao ensino superior para a classe trabalhadora, a partir daí fundamentam os elementos que determinam as bases da contrarreforma da educação, particularmente o acesso ao ensino superior, considerando sua não efetivação como direito social e sim como negócio lucrativo no Brasil. Também analisam a dualidade das respostas construídas pelo Estado brasileiro no campo da educação, situando a educação a distância como funcional às novas exigências da formação da força de trabalho e nessa dinâmica novos desafios se impõem ao projeto ético-político do Serviço Social brasileiro.

Acompanhando esse eixo de análise, no texto As particularidades do ensino superior brasileiro nos marcos do capitalismo dependente, Fabiana Maria Costa recupera o desenvolvimento histórico da universidade, marcado por uma "senilização institucional precoce" e demonstra como esta foi norteada por interesses de uma burguesia conservadora, que visa à manutenção de seus privilégios e da desigualdade social, com um "caráter ultra-elitista de educação superior". Tomando por base as análises de Florestan Fernandes, o artigo discute o desenvolvimento do ensino superior no Brasil, tendo como mediações a formação social e histórica e a revolução burguesa no país e seu caráter dependente, assinalando algumas tendências mais recentes na educação superior, as quais apontam para uma atualização do conservadorismo e da categoria de "reforma universitária consentida". Por fim, a autora conclui apontando possibilidades de construção de hegemonia da classe trabalhadora no sentido de superar sua condição de subalternidade, haja vista ser a universidade um âmbito de disputa ideológica.

Nesse contexto também comparecem as contribuições do artigo Universidade e cidadania: considerações sobre o direito social à educação, de Ana Carolina Gonçalves da Silva Santos Moreira e Elisa Maria Andrade Brisola, o qual aborda o desenvolvimento da universidade no Brasil desde a sua criação até o contexto contemporâneo de contrarreformas, relacionando panoramicamente as discussões que perfazem a lógica de implantação, expansão, acesso e permanência no ensino público superior. Destacam-se as expressões de continuidades de nossa histórica dependência colonial, assim como a cidadania regulamentada por políticas fragmentadas e focalizadas nos mais pobres. Ao final deste artigo constata-se a necessidade da consolidação de políticas que favoreçam a permanência e a conclusão do curso superior, além da defesa de ensino público, laico e de qualidade para todos.

Seguindo a interlocução e problematização sobre o tema do projeto classista de educação, no texto 0 enlace entre educação e desenvolvimento regional no processo de interiorização da Universidade Federal de Pernambuco, Tatianne 
Amanda Bezerra Silva e Jamerson Antônio de Almeida da Silva apresentam propõem-se a examinar as intencionalidades presentes no processo de interiorização das universidades brasileiras desenvolvido no governo Lula da Silva (2003-2010), tendo como base a experiência da Universidade Federal de Pernambuco (UFPE). Como caminho metodológico adotado utilizam da abordagem qualitativa, revisão de literatura e análise de documentos e publicações sobre o assunto.

O texto Serviço Social brasileiro: da gênese contraditória às atuais possibilidades ético-políticas, de Leidiane Souza de Oliveira, apresenta pesquisa bibliográfica para discutir o Serviço Social brasileiro no auge de oito décadas a partir das particularidades brasileiras atuais. Considerando as quase duas décadas do século XXI, o Brasil enquanto país periférico no circuito do capital mundial, diante profunda crise política com escândalos de corrupção e desmonte das legislações que regulam a proteção social e os direitos trabalhistas, acentuando as desigualdades entre as classes, evidenciam implicações que resvalam no cotidiano profissional de assistentes sociais nos mais distintos espaços em que se inserem. Diante de tais determinações a autora reintroduz a contradição histórica da profissão de atender simultaneamente interesses de classes antagônicas, diante das recentes contradições entre os limites postos no contexto histórico dos primeiros anos do presente século e as possibilidades organizativas de uma resistência coletiva, cujos fundamentos ético-políticos, pilares do projeto profissional crítico, articulam-se às lutas sociais mais amplas como caminho possível para construção deu ma nova ordem societária.

Alessandra Ximenes da Silva, Thaísa Simplício Carneiro Matias, Mônica Barros da Nóbrega no artigo Pesquisa e conhecimento da realidade no Serviço Social, elaboraram um ensaio teórico que prioriza o debate baseado nos fundamentos ontológicos do ser social, de modo articulado com os desafios e potencialidades na realidade contemporânea com o objetivo de analisar a trajetória histórica da pesquisa e a produção de conhecimento na área e sua relevância para fundamentar o exercício profissional. O estudo ressalta que apesar do recente acúmulo teóricometodológico, a profissão vem contribuindo para o desvelamento da realidade, inclusive para outras áreas do conhecimento, em uma perspectiva vinculada aos interesses da classe trabalhadora. Reafirma que a pesquisa e o conhecimento da realidade foram fundamentais para que o Serviço Social se consolidasse como área de conhecimento e como uma nova competência sociopolítica e teóricoinstrumental, no sentido de apreender o movimento da realidade.

O texto Pós-Graduação e trabalho docente do assistente social: desafios nas federais, de Janaina Lopes do Nascimento Duarte, elabora uma análise a partir de pesquisa elaborada junto a docentes de Universidades Federais localizadas nas regionais nordeste e leste da ABEPSS com o objetivo de mapear as atividades docentes realizadas e como a intensificação do trabalho vem se expressando. Os dados levantados na pesquisa por meio de questionário apresentam dimensões da realidade que atravessam o trabalho docente, trazendo problematizações acerca do produtivismo acadêmico e o risco de sua naturalização, uma vez que os critérios que

Temporalis, Brasília (DF), ano 18, n. 35, jan./jun. 2018. 
para avaliação do trabalho docente são externos e, muitas vezes, desconsideram a dinâmica e condições nas Universidades.

O texto Formação profissional em Serviço Social em Natal (RN): desafios e perspectivas, de Taise Cristina Gomes Clementino Negreiros, a partir de percurso metodológico que englobou entrevistas, grupos focais, levantamento documental e bibliográfico em cursos de Serviço Social presencial e a distância, traz reflexões acerca da formação profissional e seus desafios na cidade de Natal/RN. O texto indica as diferenças que atravessam a formação presencial e a distância, e demonstra como as tendências atuais do ensino superior incidem fortemente na formação profissional, trazendo desafios que devem ser considerados para a defesa das Diretrizes Curriculares da ABEPSS.

As autoras Luciana Gonçalves Pereira de Paula, Ana Cláudia Leiroz Nacarat, Camila Martins da Silva, no texto A proposta das Oficinas nas Diretrizes Curriculares: elementos para debate, apresentam uma análise da experiência desenvolvida na Faculdade de Serviço Social/UFJF junto às Oficinas de Trabalho Profissional e/ou Supervisão de Estágio como estratégias pedagógicas que compõe a lógica curricular das Diretrizes Curriculares da ABEPSS. O texto apresenta a utilização nestas Oficinas de metodologias como Ciclos Pedagógicos e o Portfólio Reflexivo como principais instrumentos de acompanhamento e avaliação processual dos/as estagiários/as e abordam a visão dos discentes acerca desta experiência.

No artigo As contradições da assistência estudantil no contexto das contrarreformas, de Cilene Sebastiana da Conceição Braga e Jacqueline Suellen de Sousa Chaves, as autoras refletem sobre o Programa Permanência, a partir da experiência da Universidade Federal do Pará (UFPA), problematizando sua configuração e contradições, além de analisar a condição dos alunos de Graduação da UFPA atendidos pelo programa no ano de 2015, no campus Belém. O artigo problematiza, de um lado, como os discentes devem apresentar-se em situação de negação de direitos e, por outro, como este Programa tem se caracterizado pela complementaridade, ou como única fonte, no acesso à renda e outros bens socialmente produzidos aos discentes pauperizados.

O texto Transformações sociais e Serviço Social: a precarização do trabalho na assistência estudantil, de Sheine Santos do Nascimento e Maria Célia Correia Nicolau, discute a Assistência Estudantil sob a ótica dos profissionais de serviço social que atuam na Política de Assistência Estudantil dos Institutos Federais de Educação. O artigo apresenta reflexão sobre como a expansão das IFEs nos últimos anos, contraditoriamente, efetiva uma ampliação do mercado de trabalho para o assistente social, mas sob forte impacto da precarização das condições de trabalho que se expressa em diversas formas.

Mariana Rosa Alves Ladeira e Hilda Maria Gonçalves da Silva no texto (Des)Caminhos Do Sistema De Cotas Brasileiro, por meio de pesquisa bibliográfica e documental, apresentam as condições e processos que culminaram com a construção do atual sistema de cotas no Brasil. As autoras problematizam as

Temporalis, Brasília (DF), ano 18, n. 35, jan./jun. 2018. 
lacunas presentes na atual constituição do sistema de cotas apontando para a necessidade de rever os critérios, e como estes ainda convivem com as práticas meritocráticas e seletivas presentes nas universidades públicas.

Encerrando a seção temática Ana Cristina Oliveira de Oliveira, no artigo Conservadorismo, Banco Mundial e Serviço Social: o (neo)desenvolvimentismo e as reformas sociais, nos revela os resultados parciais de pesquisa documental que estuda a "nova" sociabilidade do capital e suas manifestações a partir dos anos 2000 , tendo como norteador as estratégias de desenvolvimento no "combate" à pobreza. O texto discute os processos potencializados pelas políticas neoliberais e as intituladas (neo) desenvolvimentistas no Brasil que resgatam o reformismo social e o conservadorismo, edificando um pensamento único na contramão da construção do projeto ético-político profissional. A autora nos mostra, ainda, como parte dessa estratégia, a investida do Banco Mundial como um interlocutor direto na ação política e econômica nos países de capitalismo dependente, entendendo que a abordagem conservadora que se apresenta na ação política é constitutiva da dinâmica de reprodução do capital e do tratamento na relação entre a acumulação do capital e seus impactos na força viva de trabalho. O texto conclui que o discurso de defesa das atuais "reformas" sociais implica na roupagem mais humana do capitalismo e na retomada do conservadorismo na profissão, trazendo para o Serviço Social o desafio de aproximar-se dos movimentos sociais organizados no horizonte da organização da classe trabalhadora no sentido da contra-ordem burguesa e da desnaturalização da "questão social".

Abrindo os artigos de temas livres, o texto Parâmetros para a atuação de assistentes sociais na política de saúde: o significado no exercício profissional, de Débora Cristina da Silva e Tânia Regina Krüger identifica o significado que os Parâmetros para a Atuação de Assistentes Sociais na Política de Saúde representam para o exercício profissional no âmbito hospitalar. No artigo, o documento base que serve de subsídio para atuação do Serviço Social na saúde publicado pelo Conselho Federal de Serviço Social (CFESS) passa por uma reflexão sobre o seu significado e uma avaliação sobre em que medida representa adensamento teóricometodológico, político e operativo para o exercício profissional no cenário atual. A pesquisa que fundamenta tais debates se caracterizou como exploratória e qualitativa, por meio da realização de grupos focais com assistentes sociais que atuam em dois hospitais da grande Florianópolis. Os resultados apresentados pelas autoras apontam que há um superficial conhecimento do referido documento, sendo possível constatar que há, por parte dos profissionais, uma visão sobre a importância do seu significado voltada aos eixos norteadores de atuação.

Em Envelhecimento e velhice: protagonismo, temporalidade e desafios, Karine Kátia Iria Luiz, Maria das Dôres Saraiva de Loreto, Simone Caldas Tavares Mafra e Marco Aurélio Marques Ferreira buscam compreender o significado do envelhecimento e da velhice para idosos que participam do Conselho Municipal do Idoso, em cidades da região da Zona da Mata mineira. Com base em pesquisa qualitativa, os autores concluem que o significado do envelhecimento e da velhice para os idosos entrevistados tem relação direta com o seu contexto de vida e

Temporalis, Brasília (DF), ano 18, n. 35, jan./jun. 2018. 
experiências, destacando-se por aspectos ligados ao protagonismo, à temporalidade e aos desafios do dia-a-dia.

O artigo $O$ empoderamento das mulheres e a Lei Maria da Penha como Tecnologia de Gênero: possibilidades com os estudos feministas e de gênero para o Serviço Social, de Thiago F. Sant'Anna, analisa a Lei 11.340/06, conhecida por Lei Maria da Penha, como uma tecnologia de gênero voltada para o enfrentamento de casos particulares de violência contra as mulheres e como meio para a transformação das relações desiguais de gênero. Com base em contribuições dos estudos feministas e de gênero, do debate do Serviço Social e do pensamento de Michel Foucault, o autor trata a violência contra as mulheres como uma das expressões da questão social, o que a constitui como uma relevante área de atuação de assistentes sociais.

Gessica Martins Mororó e Aline de Carvalho Martins, em Expectativas de gestantes sobre Rede de Apoio, abordam o cuidado infantil como uma esfera da reprodução da força de trabalho, a qual, segundo as autoras, não vem sendo assumida pelo Estado, mas tratada como responsabilidade da família, especialmente das mulheres. Com base em um estudo qualitativo, o artigo apresenta as expectativas de rede de apoio pessoal e estatal em gestantes com idade igual ou superior a 35 anos, e aponta, como um de seus resultados, que as gestantes tendem a pensar em estratégias mais práticas e menos politizadas para a solução do cuidado infantil, buscando resolver as questões de gênero somente no âmbito privado.

A partir de pesquisa realizada junto aos profissionais de uma unidade de saúde na cidade de Currais Novos (RN), lara de Souza Januário e Priscilla Brandão de Medeiros, no artigo Como a gente lida? A atuação da estratégia de saúde da família em situações de violência conjugal, aborda a atuação da equipe de Estratégia de Saúde da Família (ESF) na problemática da violência doméstica contra mulher em sua interface na relação conjugal. A análise das percepções desses profissionais evidencia aspectos conceituais da violência e permitem uma breve avaliação dos serviços que compõe a rede de enfrentamento à violência contra a mulher e uma avaliação da própria intervenção profissional. Articulando a discussão de gênero e a teoria crítica dialética, oferece reflexões sobre os preconceitos, sobre a influência cultural e histórica do patriarcado e sobre a importância da assistência à mulher vítima de violência.

Em Serra do silêncio: violência sexual em Maranguape (CE), Patrícia Emmanuelle Mello e Almeida Muniz e Francimara Carneiro Araújo abordam as respostas das políticas públicas aos casos de suspeita ou confirmação de abuso sexual infantojuvenil oriundos do distrito Serra do Lagedo, em Maranguape (CE). As autoras analisam a atuação de equipamentos públicos nos casos de abuso sexual, o perfil da vítima e do abusador, as circunstâncias da denúncia e os encaminhamentos realizados, apontando a necessidade de formulação e implantação de um circuito eficaz de atendimento aos vitimizados de abuso sexual no município.

Finalizando esta edição, Elizabeth da Silva Alcoforado, no artigo Abuso sexual: formação profissional, condições de enfrentamento da proteção social especial e o 
adoecimento do profissional que atua no atendimento às vítimas, aborda as dificuldades de operacionalização das ações voltadas às vítimas de violência sexual por limitações institucionais, de formação, de apoio e falta de capacitação adequada, o que, muitas vezes, leva a própria equipe a buscar formas criativas para suportar o peso do cotidiano permeado por histórias de violências. A autora ressalta que é a revelação da violência sexual, mediante relato da vítima junto aos profissionais qualificados, que possibilita a exposição de toda uma dinâmica da violência doméstica, e, neste sentido, a atuação em rede torna-se um ponto crucial, haja vista que várias demandas se apresentam, requerendo, com isso, que o trabalho seja fortalecido entre os técnicos de atendimento direto, como também com a equipe de referência e contra referência.

Convidamos todos e todas à leitura e desejamos que seja prenhe de reflexões e críticas!

"Quem é de luta, Resiste!"

Gestão 2017-2018 